\title{
A Highly Efficient Approach to the Synthesis of Complex a-Glycosyl Phosphosaccharides
}

\author{
Yunnan University \\ Xiaojuan Zhang \\ Yunnan University \\ Yutong Yang \\ Yunnan University \\ Jiahao Ding \\ Yunnan University \\ Yun Zhao \\ Yunnan University \\ Hongbin Zhang \\ Yunnan University
}

Yugen Zhu ( $\nabla$ zhuyg86@163.com)

\section{Article}

Keywords: a-glycosyl phosphosaccharides (GPSs), synthesis

Posted Date: July 12th, 2021

DOl: https://doi.org/10.21203/rs.3.rs-669845/v1

License: (c) (i) This work is licensed under a Creative Commons Attribution 4.0 International License. Read Full License

Version of Record: A version of this preprint was published at Nature Communications on January 20th, 2022. See the published version at https://doi.org/10.1038/s41467-022-28025-0. 


\title{
A Highly Efficient Approach to the Synthesis of Complex $\alpha$-Glycosyl Phosphosaccharides
}

\begin{abstract}
A highly efficient and stereoselective approach to the synthesis of biologically important and complex $\alpha$-glycosyl phosphosaccharides (GPSs) has been disclosed, employing direct gold(I)catalyzed glycosylation of the weakly nucleophilic phosphoric acid acceptors. The broad substrate scope is demonstrated with more than 45 examples, including glucose (Glc), xylose, glucouronatose, galactose (Gal), mannose (Man), rhamnose (Rha), fucose (Fuc), 2-N $3-2$-dexoxymannose $\left(\mathrm{ManN}_{3}\right), 2$ $\mathrm{N}_{3}$-2-dexoxyglucose $\left(\mathrm{GlcN}_{3}\right)$, 2- $\mathrm{N}_{3}$-2-dexoxygalactose $\left(\mathrm{GalN}_{3}\right)$ and unnatural carbohydrates. Moreover, the glycosyl phosphotriester prepared herein was successfully applied to the one-pot synthesis of a GPS from Leishmania donovani, and an effective preparation of a trisaccharide diphosphate of GPS fragments from Hansenula capsulate via iterative elongation strategy is realized.
\end{abstract}

\section{Introduction}

GPSs represent a large and important family of complex glycans, which are ubiquitously distributed in bacteria, yeasts, protozoan parasites, and animals, and exhibit numerous bio-functions including bacterial infections, cell adhesive, immunoresponse, and antimicrobial (Figure 1B) ${ }^{1-5}$. The GPSs consist of anomeric glycosyl phosphates in which the anomeric position of one constituent glycan was linked to another one mainly by $\alpha$-type phosphodiester linkage (Figure 1A). In the process of carbohydrate metabolism, the constituent glycosyl phosphates (GPs) are significant intermediates ${ }^{6}$. Synthetically, protected GPs have been utilized as effective glycosyl donor reagents ${ }^{7}$, and under the catalysis of bis-thiourea, the armed GPSs proceed an $\mathrm{S}_{N}-2$ glycosylation pathway ${ }^{8}$. Despite the significance of GPSs, efficient approaches to access GPSs are rather limited: isolation from cell culture hardly affords homogeneous sample and chemical synthesis remains challenging due to the character of complex structure. Accordingly, efficient methods of constructing homogeneous GPSs and GPs are still in great demand. 


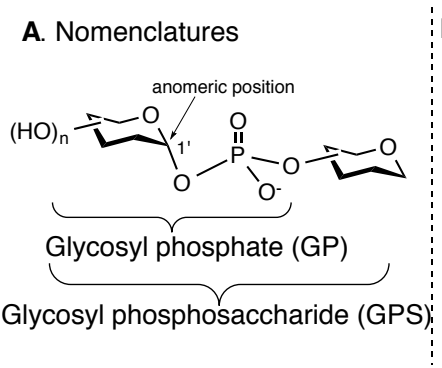

B. Representative bioactive phosphosaccharides

$\mathrm{NH}_{2}$

HO

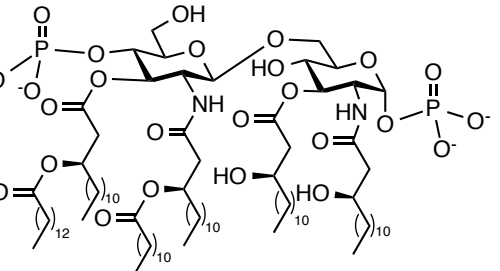

Lipid A from E. coli (endotoxin)

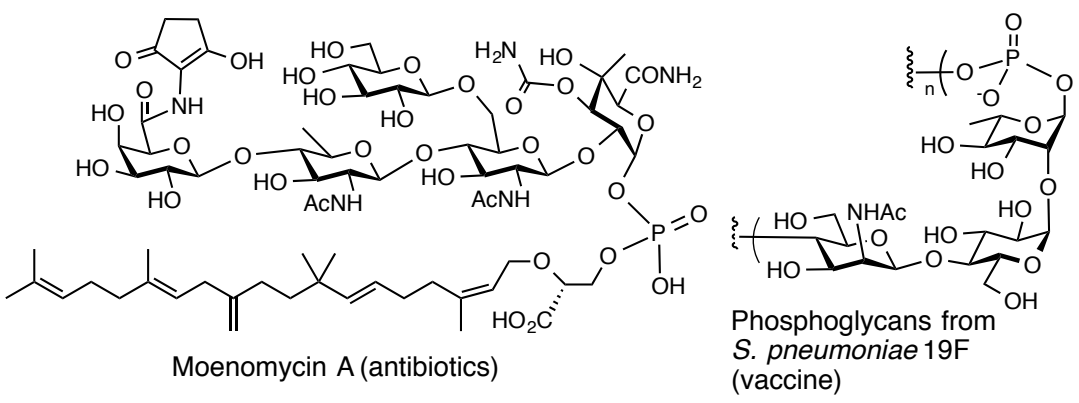

Figure 1. Nomenclatures for Glycosyl Phosphate and Phosphosaccharide (A) and Representative Bioactive Phosphosaccharides (B)

In addition to intrinsically labile character, the anomeric stereocontrol of forming $\alpha$-GPSs, most of which assume 1,2-cis configuration, is regarded as a challenging task ${ }^{9-17}$. The synthetic method of $\mathrm{H}-$ phosphonate chemistry has found extensive applications in the synthesis of $\alpha$-GPSs, while two-step transformations of nucleophilic displacement and oxidation are inevitable (Scheme 1A) ${ }^{2,18,19}$. Nevertheless, the resulted phosphate anions render product incompatible with follow-up or late-stage chemical modifications to increase molecular complexity and diversity ${ }^{20}$. The alternative approach employing phosphoramidite displays great success in installation of phosphoester, yet is rarely applied to synthesis of anomeric GPS probably due to issues of diastereo-selectivity and undesired oxidative cleavage reaction (Scheme 1B) ${ }^{21-23}$. 


\section{Scheme 1. Profile of approaches to glycosyl phosphosaccharides}

A) The H-phosphonate method:

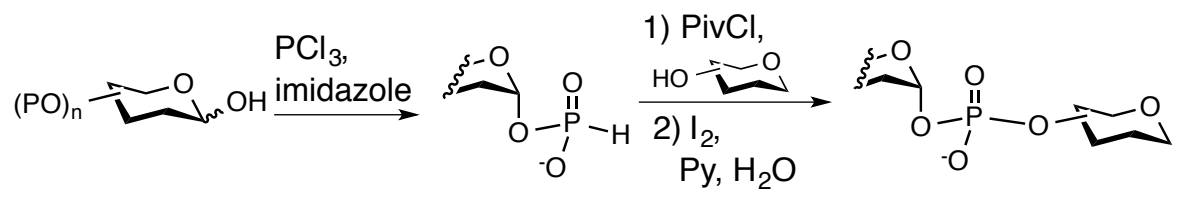

B) The phosphoramidite method:

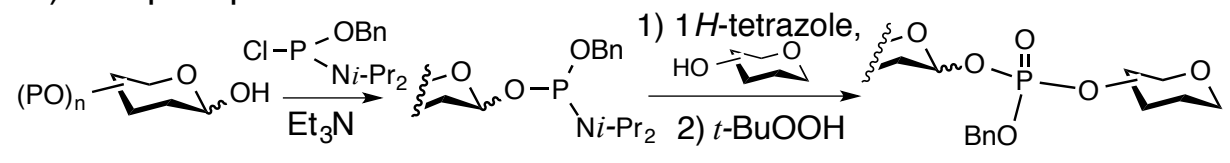

C) The glycosylation methods:

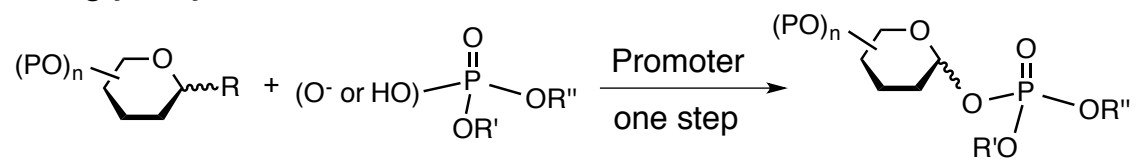

$\mathrm{R}=\mathrm{OC}(\mathrm{NH}) \mathrm{CCl}_{3}, \mathrm{SPh}, \mathrm{OH}, 3$-methoxypyridin-2-yl, 4-pentenyloxy etc.

D) This work:

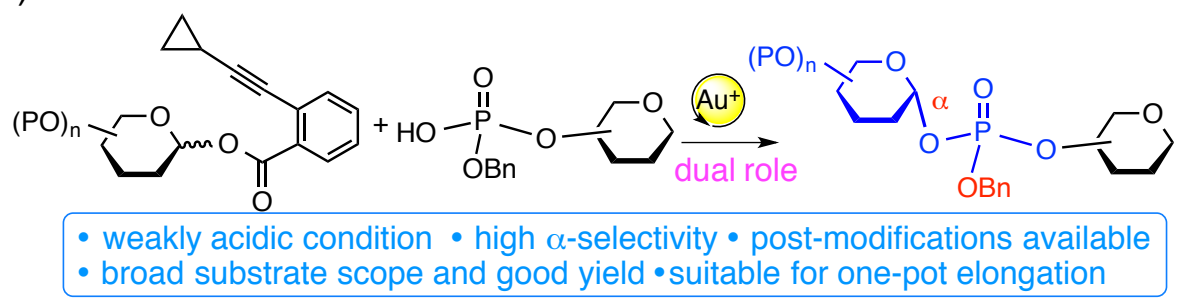

One-step and direct glycosylation of phosphate acceptors with glycosyl donors represents a convergent and concise method for the synthesis of $\alpha$-GPSs, which does not require oxidation transformation (Scheme 1C). This glycosylation strategy to access $\alpha$-GPSs was previous realized by utilizing glycosyl trichloroacetimidate as donor and the weak nucleophile of phosphoric acid as acceptor under the action of strong $\mathrm{acid}^{24}$, and later, by a panel of donors with different leaving groups (e.g. SPh, 3-methoxypyridin-2-yl, pentenyloxy ${ }^{25-31}$. The efficiency of these glycosylation reactions with phosphates as acceptors remains unmet: 1) the yield was deteriorated when strong acid was used to realize $\alpha$-stereoselectivity ${ }^{24}, 2$ ) stoichiometric base was applied to preserve the entity of GPs, but leading to poor 1,2-cis stereoselectivity ${ }^{28}, 3$ ) only a handful of complex disaccharide GPSs were accessed by using the direct glycosylation strategy with phosphate anion as acceptor ${ }^{25}$.

Catalytic glycosylation methods have emerged as an appealing approach to the synthesis of carbohydrates, which feature less promoter and waste, and high efficiency ${ }^{32}$. Among those, alkynylphilic gold(I) catalysis has been extensively applied in the syntheses of numerous complex glycans and glyconjugates ${ }^{33}$, along with other natural products ${ }^{34}$, by exploiting the compatibility with oxygen-containing functionalities ${ }^{35}$. Especially, glycosyl donor with ortho-alkynylbenzoate as leaving group first introduced by $\mathrm{Yu}$ and coworkers can glycosylate a variety of acceptors ${ }^{36,37}$. Nevertheless, 
the glycosylation of exceedingly poor nucleophile of phosphoric acid remains elusive, which entails mild conditions free from competitive nucleophilic species. We herein disclose a stereoselective and general approach to the synthesis of $\alpha$-GPs and $\alpha$-GPSs via a gold(I)-catalyzed glycosylation method with glycosyl ortho-alkynylbenzoate as donor and weakly nucleophilic phosphoric acid as acceptor. While the alkynylphilicity of gold(I) catalysis has been widely investigated and applied, the Lewis acid property when oxygen-containing functionalities is activated by gold(I) remains much less explored. Herein, both the alkynylphilicity and weak acidity of gold(I) catalyst are capitalized on to initiate the glycosylation reaction and promote epimerization to $\alpha$-anomer, respectively (Scheme 1D). Moreover, the anomeric effect of phosphoric acid in the glycosylation reaction is also exploited to direct the $\alpha$ selectivity under the present weakly acidic condition ${ }^{38,39}$.

\section{Results and Discussions}

To test the validity of this proposal, tetrabenzyl glucoside 1a was examined with a structurally simple acceptor of phosphoric acid dibenzyl ester $\mathbf{2 a}$ (Table 1). Initial experiment gave promising results with good yield (88\%) and $\alpha$-selectivity $(\alpha / \beta=2.8 / 1$, entry 1$)$. Thus, detailed optimizations were subsequently conducted by tuning reaction temperature, solvent and additives. As depicted in Table 1, lowering temperature was not effective $(83 \%, \alpha / \beta=2 / 1$, entry 2$)$; varying the anion in the catalysis with -OTf diminished $\alpha$-selectivity (entry 3); switching to solvent of ether and additive of $\mathrm{Ph}_{3} \mathrm{P}=\mathrm{O}$ did not provide satisfactory results though they were effective in the case of alcohol acceptor (entry 4-6) ${ }^{11}$. Gratifyingly, the diastereoselective ratio was raised to $10 / 1$ by an added $\operatorname{HOTf}$ ( 0.1 equiv.), which is supposed to thermodynamically equilibrated $\beta$-anomer to the $\alpha$-one, but compromise the overall yield (62\%, entry 7). In contrast, heterogenous acidic $\mathrm{H}^{+}$resin did not affect the diastereoselectivity (entry 8). Hence, the homogeneous Lewis acid of gold(I) catalysis was anticipated to activate the armed glycosyl phosphate under an elevated temperature. Indeed, after complete glycosylation of $\mathbf{2 a}$ at $0{ }^{\circ} \mathrm{C}$ for $0.5 \mathrm{~h}$, keeping the mixture at $60{ }^{\circ} \mathrm{C}$ for $2 \mathrm{~h}$ in non-coordinating $\mathrm{ClCH}_{2} \mathrm{CH}_{2} \mathrm{Cl}$ (DCE) for anomerization produced the $\alpha$-anomer in good selectivity $(\alpha / \beta=9 / 1)$ without deteriorating yield $(87 \%$, entry 9). Further elevation of temperature $\left(75^{\circ} \mathrm{C}\right.$ and $\left.95^{\circ} \mathrm{C}\right)$ resulted in a drop of yield or decomposition of product (entry 10,11). Fortunately, increasing the equivalence of donor 1a to 1.5 relative to acceptor 2a (1.0 equiv.) reached an exceptional ratio of $16 / 1$ in an excellent yield of $93 \%$ (entry 12). 
Table 1. Optimizations of the Reaction Conditions ${ }^{a}$

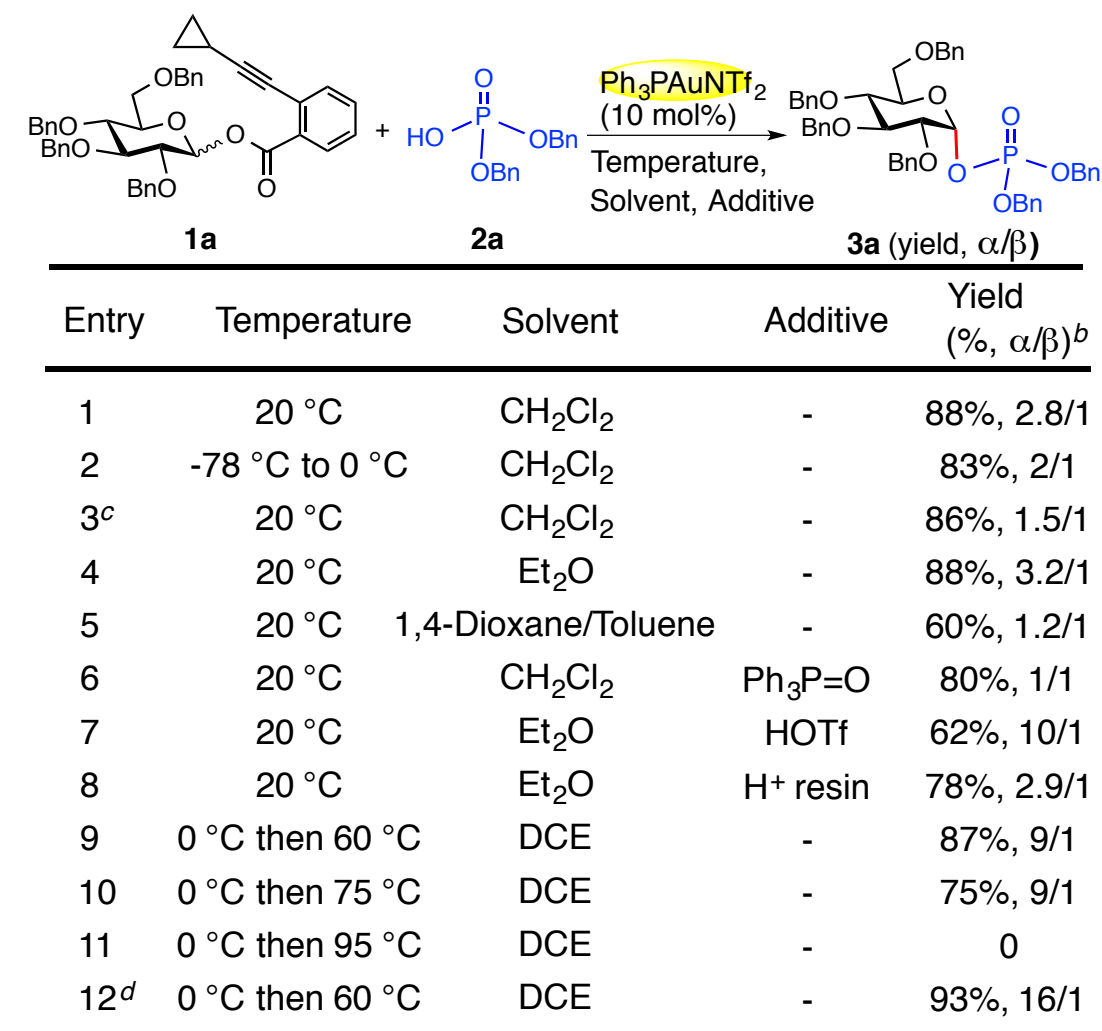

${ }^{a}$ Reaction condition: $1 \mathbf{a}(0.05 \mathrm{mmol}), \mathbf{2 a}(0.075 \mathrm{mmol})$, solvent $(1.0$ $\mathrm{mL}$ ), [Au] (10 mol\%), $5 \AA$ MS. $b$ Yields of isolated products, and ratios determined by HPLC. ${ }^{c} \mathrm{Ph}_{3}$ PAuOTf was used instead. ${ }^{d}$ Optimized condition: 1a (0.075 mmol) and $\mathbf{2 a}(0.05 \mathrm{mmol}), \mathrm{Ph}_{3} \mathrm{PAuNTf}_{2}(10$ $\mathrm{mol} \%)$, DCE $(1 \mathrm{~mL}), 0{ }^{\circ} \mathrm{C}, 30 \mathrm{~min}$, then $60^{\circ} \mathrm{C}, 2 \mathrm{~h}$

Next, we wondered whether this gold (I)-catalyzed glycosylation strategy was amenable to various glycosyl donors outfitted with different protecting groups or configurations (Table 2). First, donor 1b, of which the $\mathrm{BnOCH}_{2}$ moiety is omitted compared to $\mathbf{1 a}$, delivered the expected xylosyl phosphate $\mathbf{3 b}$ in good yield and diastereoselectivity $(78 \%, 11 / 1)$ by utilizing the aforementioned protocol. Replacing

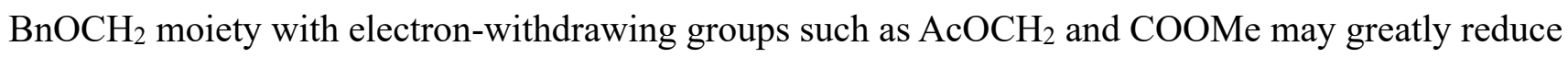
the reactivity of donor, thereby causing difficulty in epimerization. Luckily, the 6-O-Ac product (3c) could be reached in a diastereoselective ratio of 12/1 merely at room temperature, of which $\alpha$-selectivity is presumably dominated by anomeric effect ${ }^{38,39}$. For the other one equipped with COOMe, the product (3d) can be epimerized to enrich $\alpha$-anomer (9.7/1) under higher temperature of $100{ }^{\circ} \mathrm{C}$ with a good yield of $87 \%$.

Consequently, this strategy was extended to a variety of donors including Gal, Man, ManN 3 , Rha, Fuc, GlcN 3, GalN $_{3}$ and unnatural carbohydrates (Table 2). For the production of those with highly anomeric effect and dominated by steric hindrance, such as galactosyl phosphate (3e and $\mathbf{3 e}$ '), mannosyl phosphate (3f and 3f'), disarmed 2-N3-2-dexoy-mannosyl phosphate (3g), rhamnosyl 
phosphate (3h) and fucosyl phosphate (3i), an operationally simple procedure at room temperature was effective to access desired products in highly diastereoselective manners and excellent yields. However, switching to phenyl tetrabenzyl-1-thio-mannoside which was preactivated with $p$-TolSCl and AgOTf, followed by addition of $\mathbf{2 a}$, gave only byproduct $\mathbf{3 p}$ derived from intramolecular cyclization ${ }^{40}$. Among those, $\mathbf{3 g}$ represents constituent unit derived from capsule polysaccharide of Neisseria meningitidis $\mathrm{A}^{41}$. The straightforward syntheses of extremely unstable diphenyl phosphate $\mathbf{3} \mathbf{e}^{\mathbf{8}}$ and $\mathbf{3 f}$ ' demonstrate the utility of this strategy for directly glycosylating weakly nucleophilic phosphoric acid. Moreover, $\mathbf{3 f}$ can be obtained on a $1.2 \mathrm{~g}$ scale with low catalytic loading of $\mathrm{Ph}_{3} \mathrm{PAuNTf}_{2}(0.5 \mathrm{~mol} \%)$ albeit in slightly decreased diastereoselectivity $(17 / 1)$ and yield $(87 \%)^{42}$. The deprotected form of $\mathbf{3 f}$ might serve as replacement therapy for the disease of congenital disorder of glycosylation type Ia, which is under clinical trial ${ }^{43}$. Interestingly, 1,2-cis $\alpha$-fucosyl phosphate 3i was obtained even with neighboringparticipating Bz situated at 2-O, demonstrating the strong anomeric effect in the case of phosphoric acid as acceptor. However, the diastereoselectivity can be reversed by adding extra base of $\mathrm{iPr}_{2} \mathrm{NEt}$ (0.2 equiv.) to form phosphate anion as acceptor.

Because of the distinct nature of $\mathrm{N}_{3}$ substituent in comparison with $\mathrm{OBn}$, formation of 1,2-cis $\alpha$-Dglycosamine glycosidic bond remains elusive in the case of alcohols as acceptors ${ }^{14-17}$. Although the azido substituted glycosyl phosphates are resistant to epimerization at high temperature, donors of tribenzyl GlcN ${ }_{3}$ and $\mathrm{GalN}_{3}$ underwent smoothly coupling reactions with useful diastereoselective ratios of 8.6/1 (3j) and 7.3/1 (3k) which might find utility in the synthesis of Lipid A or other phosphosaccharides ${ }^{2,44}$

Derivatization and mimicking of natural glycosyl phosphates emerge as attractive tools to elucidate molecular mechanism of glycosyltransferases and discover novel therapeutic reagents ${ }^{45,46}$. Herein, a panel of fluorine-substituted $\alpha$-GPs (31-3o) were readily assembled via gold(I)-catalyzed glycosylation approach. Notably, the highly $\alpha$-selective outcomes are in stark contrast to the reported results of fluorine-directed glycosylation with alcohol acceptors ${ }^{47}$. 
Table 2. The Reaction Scope of Various Glycosyl Donors
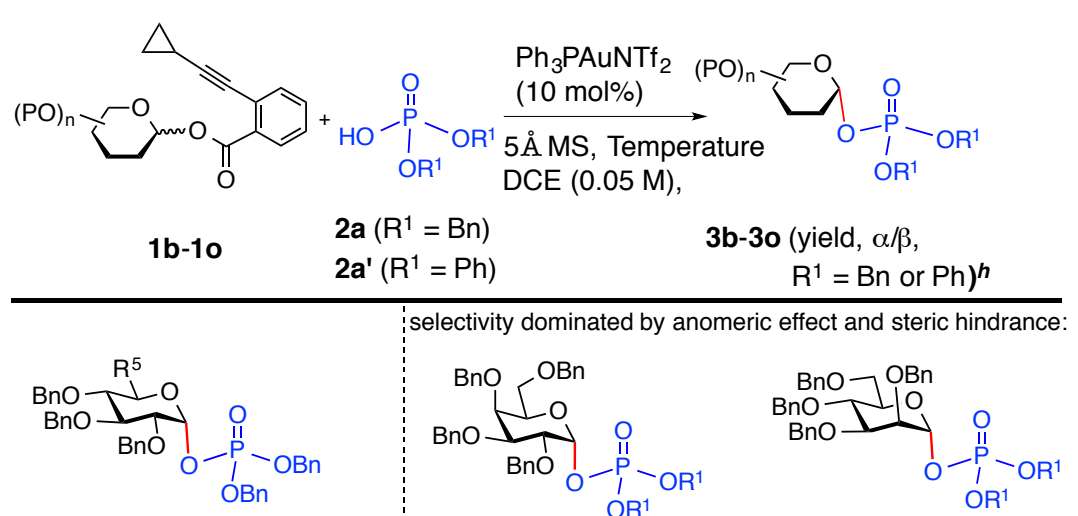

selectivity dominated by anomeric effect and steric hindrance:

3b $\left(78 \%, 11 / 1, \mathrm{R}^{5}=\mathrm{H}\right)^{\mathrm{a}}$
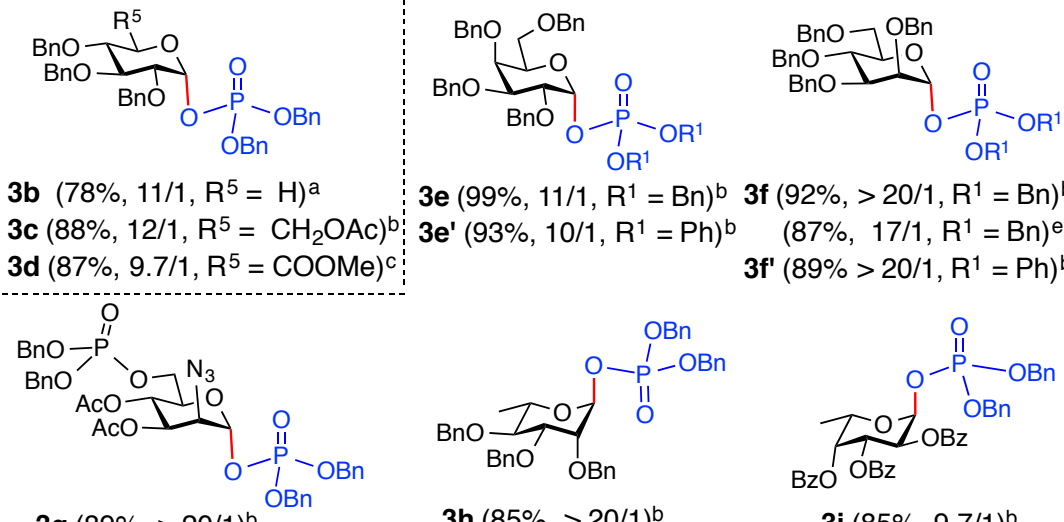

3e $\left(99 \%, 11 / 1, R^{1}=B n\right)^{b} 3 f\left(92 \%,>20 / 1, R^{1}=B n\right)^{b}$

3c $\left(88 \%, 12 / 1, \mathrm{R}^{5}=\mathrm{CH}_{2} \mathrm{OAc}\right)^{\mathrm{b}}: 3 \mathrm{e}^{\mathrm{\prime}}\left(93 \%, 10 / 1, \mathrm{R}^{1}=\mathrm{Ph}\right)^{\mathrm{b}} \quad\left(87 \%, 17 / 1, \mathrm{R}^{1}=\mathrm{Bn}\right)^{\mathrm{e}}$ 3d $\left(87 \%, 9.7 / 1, \mathrm{R}^{5}=\mathrm{COOMe}\right)^{\mathrm{C}}$

$3 f^{\prime}\left(89 \%>20 / 1, R^{1}=P h\right)^{b}$

$3 g(89 \%,>20 / 1)^{b}$

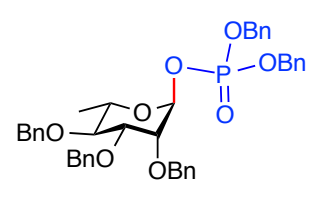

$3 h(85 \%,>20 / 1)^{b}$

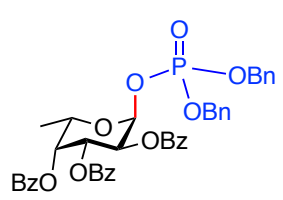

$3 \mathbf{i}(85 \%, 9.7 / 1)^{\mathrm{b}}$ $(93 \%, 1 / 20)^{f}$

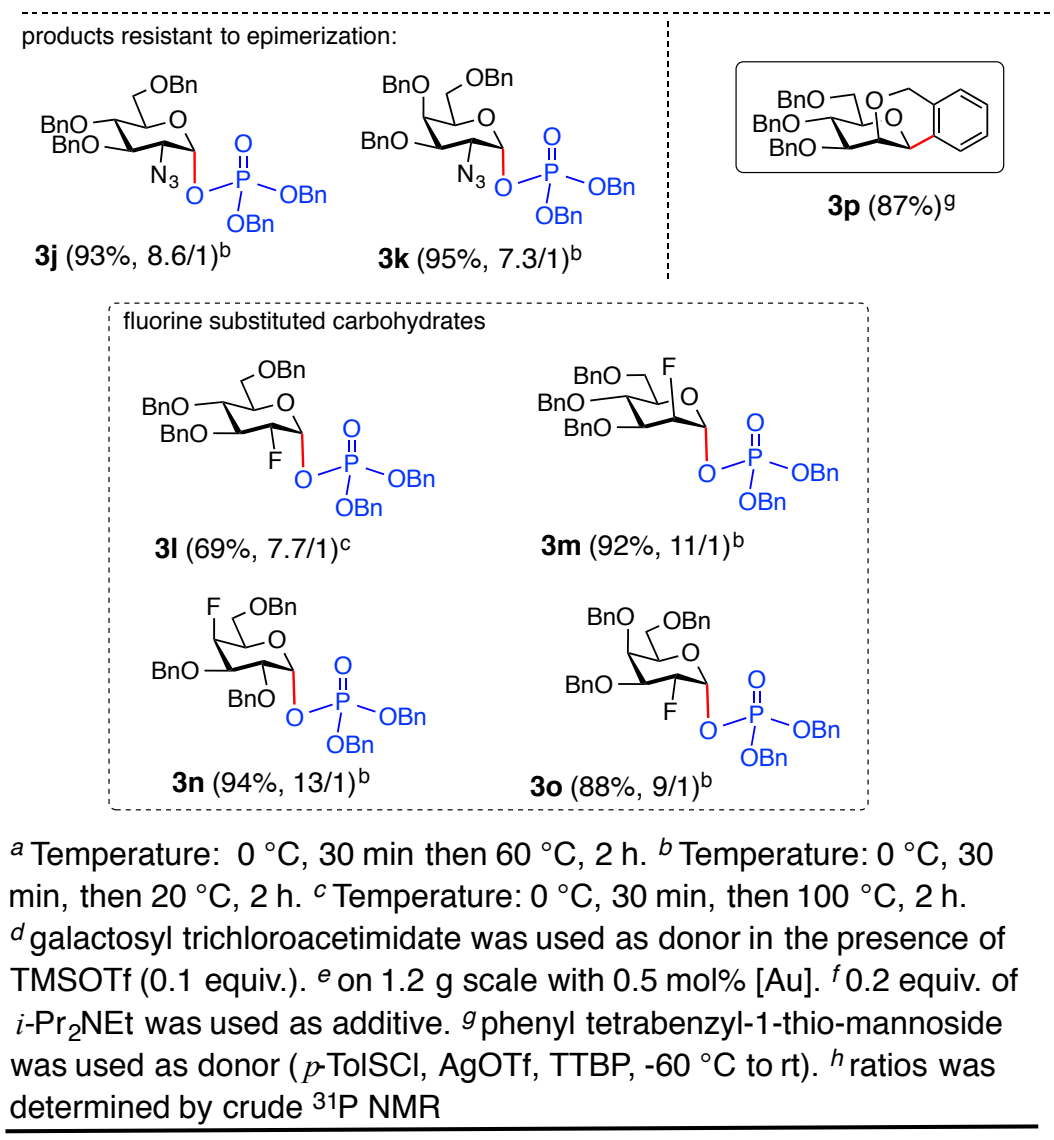

After determining the generality of various glycosyl donors which glycosylated with phosphoric acid 2a, we explored the possibility of extension to more complex phosphate nucleophiles. Thus, a set of structurally diverse acceptors of phosphoric acid glycosyl/peptidyl esters were readily prepared 
through a straightforward route of phosphorylation of alcohol and subsequent debenzylation (see SI), including 6-O-benzyloxyphosphoryl glucoside $\mathbf{2 b}$ and $\mathbf{2 c}$, sterically hindered 4-Obenzyloxyphosphoryl glucoside $\mathbf{2 d}$ and galactoside $\mathbf{2 e}$, and 3-O-benzyloxyphosphoryl glucoside $\mathbf{2 f}$ outfitted with labile groups of TBS and benzylidene (Table 3). The carbohydrates widely distributed in natural GPSs were selected as glycosyl donors (Glc (1a), Gal (1e), Man (1f), Rha (1h), GlcN 3 (1j), $\mathrm{GalN}_{3}(\mathbf{1 k})$ ), which led to twenty-seven bis-glycosyl benzylphosphotriesters. For convenience of characterization, the phosphorus chirality was eliminated by hydrogenolysis of benzyl phosphates (4a-4za), which simultaneously resulted in reduction of $\mathrm{N}_{3}(\mathbf{4 t - 4 z}, \mathbf{4 z a}, \mathbf{4 e}, \mathbf{4 j}, \mathbf{4 o})$. In detail, by using the protocol of glycosylation and subsequent anomerization, condensation of Glc donor (1a) and all the five acceptors (2b-2f) delivered the corresponding GPSs (4a-4e) in highly diastereoselective manners and yields. The donors of Gal (1e), Man (1f) and Rha (1h) with highly anomeric effect produced GPSs (4f-4s) in invariably high $\alpha$-selectivities and excellent yields. Although azide substituted substrates of $\mathrm{GlcN}_{3}$ and $\mathrm{GalN}_{3}$ are resistant to epimerization and display weaker $\alpha$ configured bias, good results were attained with consistent stereoselectivities and quantitative yields $(4 t-4 v, 4 x-4 z, 4 z a)$, except $4 w$ which was formed in low stereoselectivity (3/1). 


\section{Table 3. The reaction scope of various acceptors of phosphoric acids}

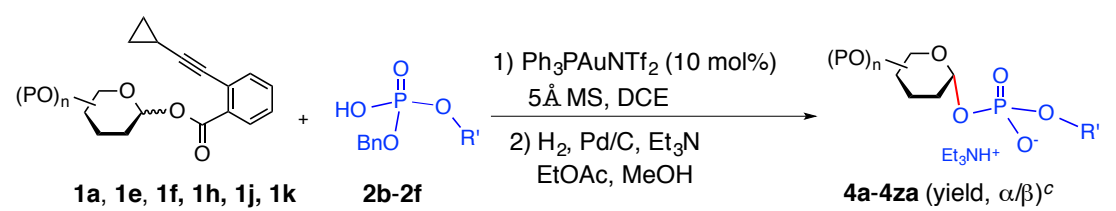

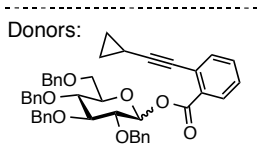

1a

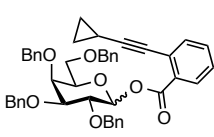

$1 \mathrm{e}$

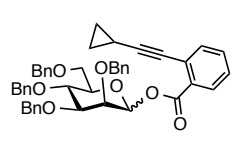

$1 f$

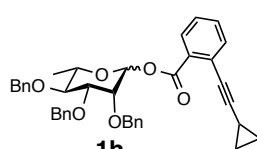

$1 \mathrm{~h}$

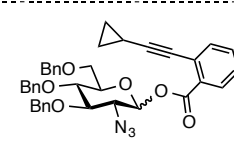

$1 \mathbf{j}$

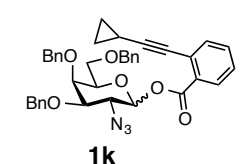

$$
\text { Acceptors: }
$$
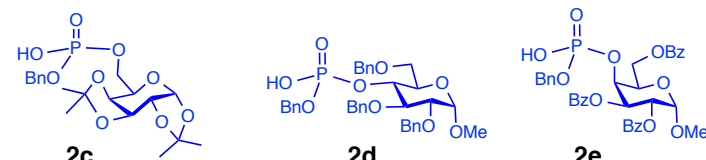

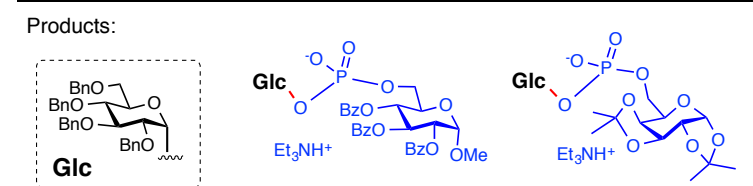

4a $(89 \%,>20 / 1)^{a} \quad 4 b(86 \%, 12 / 1)^{a}$

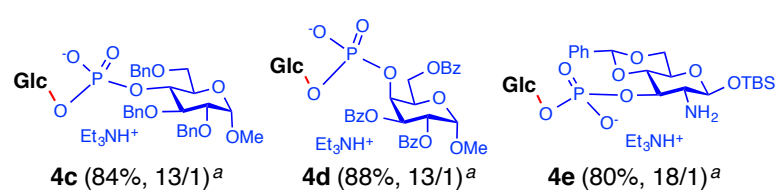

4c $(84 \%, 13 / 1)^{a}$

$$
\text { 4d }(88 \%, 13 / 1)^{a}
$$

$4 \mathrm{e}(80 \%, 18 / 1)^{a}$

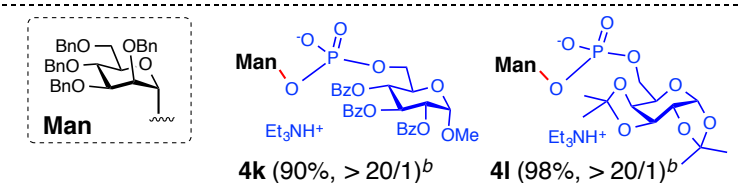

Man

$4 \mathrm{~m}(90 \%,>20 / 1)^{b}$

4n $(93 \%,>20 / 1)^{b}$

$40(96 \%,>20 / 1)^{b}$

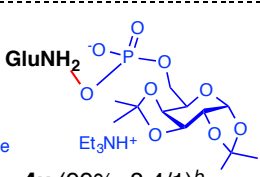
4u $(99 \%, 8.4 / 1)^{b}$

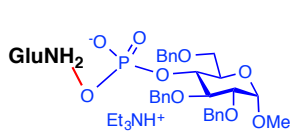

$4 \mathbf{v}(97 \%, 6.6 / 1)^{b}$

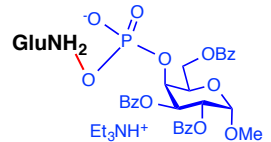

4w $(99 \%, 3 / 1)^{b}$

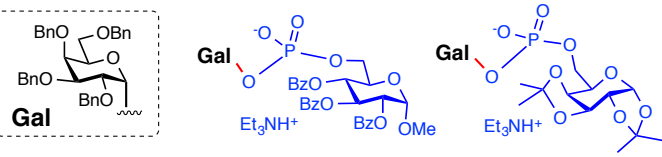

$4 \mathbf{f}(96 \%, 14 / 1)^{b} \quad \mathbf{4 g}(96 \%,>20 / 1)^{b}$
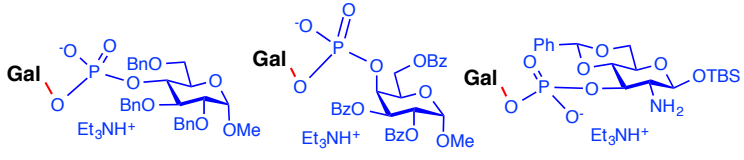

4h $(93 \%, 19 / 1)^{b}$

$4 \mathbf{i}(90 \%,>20 / 1)^{b}$

4j $(95 \%,>20 / 1)^{b}$
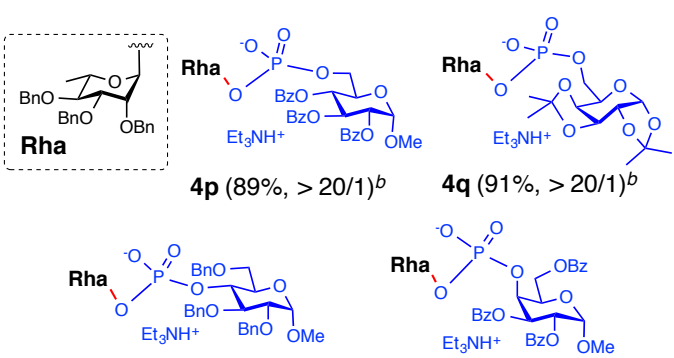

$4 \mathbf{r}(88 \%,>20 / 1)^{b}$
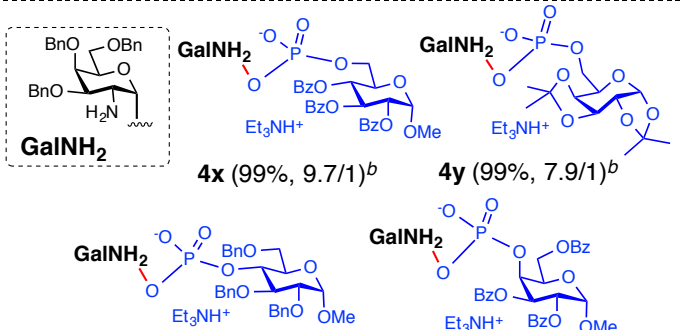

$\mathbf{4 z}(99 \%, 11 / 1)^{b}$

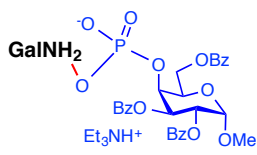

4za $(99 \%, 8 / 1)^{b}$

${ }^{a}$ Temperature: $0{ }^{\circ} \mathrm{C}, 30 \mathrm{~min}$ then $60{ }^{\circ} \mathrm{C}, 2 \mathrm{~h} .{ }^{b}$ Temperature: $0{ }^{\circ} \mathrm{C}, 30 \mathrm{~min}$, then $20{ }^{\circ} \mathrm{C}, 2 \mathrm{~h} .{ }^{c}$ ratios determined by ${ }^{31} \mathrm{P}$ NMR

Furthermore, one of phosphoglycopeptides (4zb), which are found in parasites, was concisely assembled via glycosylation of threonyl phosphate $\mathbf{2 g}$ in a stereospecific manner, albeit in a low yield of $60 \%$ because of limited solubility of $\mathbf{2 g}$ in $\mathrm{DCE}^{48}$ (Scheme 2 ). 


\section{Scheme 2. Synthesis of Phosphoglycopeptide}

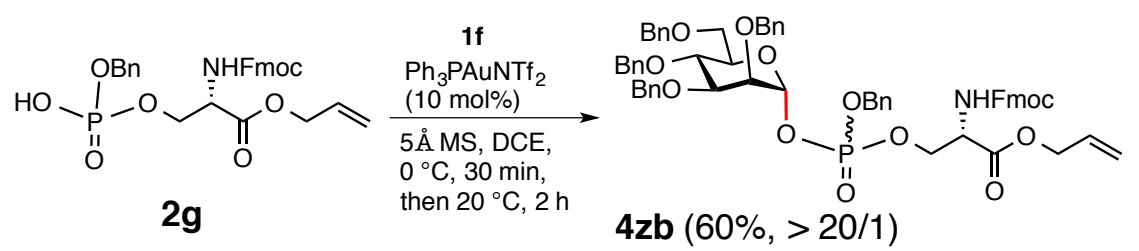

While one-pot glycosylation protocol emerges as versatile strategy to synthesize complex oligo/polysaccharides of which the units are tethered by acetal linkages ${ }^{49-51}$, this strategy is not applicable to the assembly of conventionally synthesized bis-glycosyl phosphodiester which incorporate reactive functionality of phosphate anion. Gratifyingly, bis-glycosyl benzyl phosphotriesters readily prepared in our system could serve as attractive substrates for one-pot glycosylation, and described in Scheme 3 is an example, in which linker-tethered $\mathbf{5}$ was assembled in one pot via gold(I)-catalyzed glycosylation reaction and a follow-up orthogonal coupling promoted by NIS and TMSOTf. The chirality of phosphorus atom can be eliminated by converting $\mathrm{OBn}^{-}$to $\mathrm{O}^{-}$ generating a single stereomer $(6,97 \%)$ derived from phosphosaccharide of Leishmania donovani ${ }^{1}$

\section{Scheme 3. One-pot Synthesis of GPS 6}

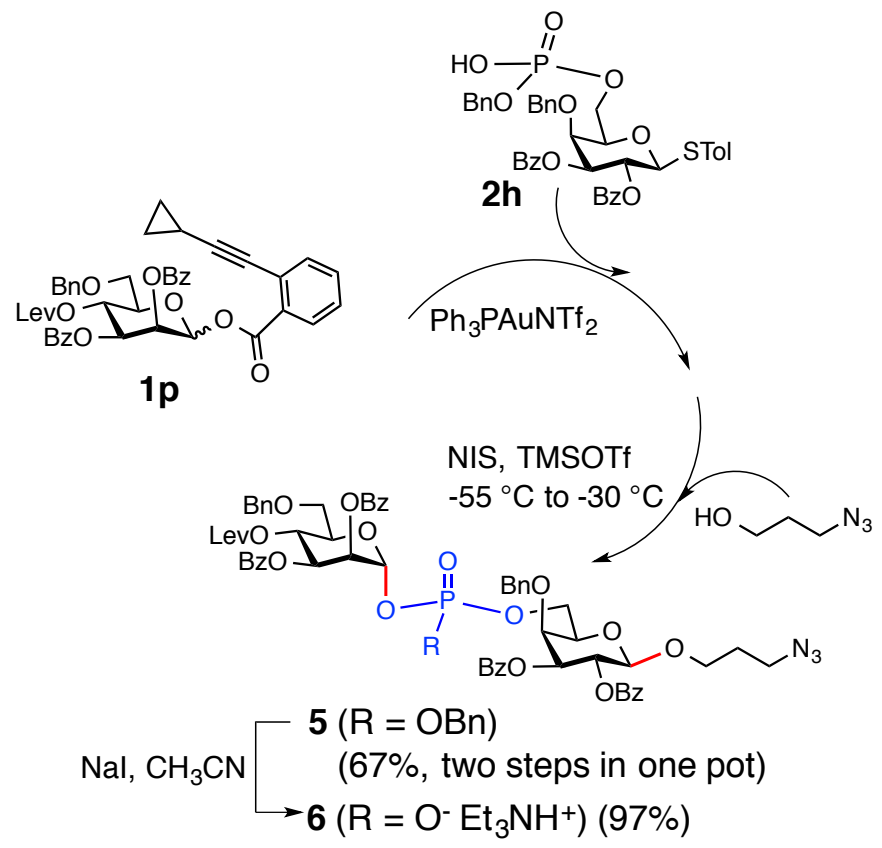

Finally, the utility of this gold(I)-catalyzed one-step approach to synthesis of GPSs was further illustrated by iterative elongation of phosphomannosyl fragments from Hansenula capsulate (Scheme $4)^{52}$. First, condensation of donor $\mathbf{1 q}$ and acceptor $\mathbf{2 i}$ furnished the desired phosphotriester 4zc. Because 4zc was resistant to preactivation by using $p$-TolSCl/AgOTf or $\mathrm{BSP} / \mathrm{Tf}_{2} \mathrm{O}$ which led to only $30 \%$ yield and armed donor with benzyl groups was prone to give cyclized byproduct (e.g. 3p) ${ }^{40,53}$, SPh was converted to ortho-alkynylbenzoate as leaving group via two steps. Next, condensation of $\mathbf{7}$ and $\mathbf{2 i}$ 
generated a trisaccharide 8 consisting of two phosphotriester funcitonalities in good yield (70\%), which was subsequently converted to trisaccharide donor 9 in a procedure similar to that for 7 . As a late-stage chemical modification on this trisaccharide, a third glycosylation reaction between donor 9 and 3azidopropanol was performed to install a linker with the two present phosphotriesters intacted. Finally, the resulting trisaccharide was globally deprotected under mild conditions to afford an amino-linker tethered trisaccharide diphosphate $\mathbf{1 0}$.

\section{Scheme 4. The synthetic route to GPS 10 via late-stage modification}
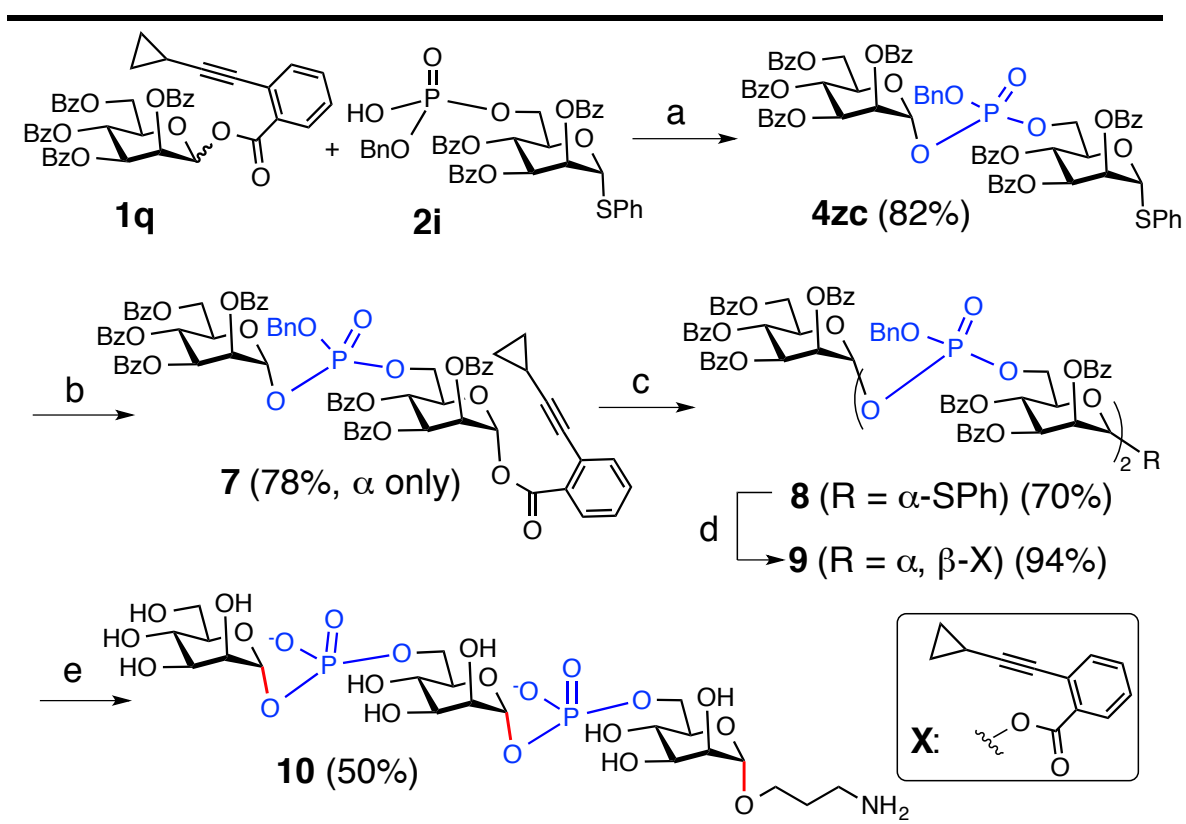

a) $\mathrm{Ph}_{3} \mathrm{PAuNTf}_{2}$ (10 mol\%), $5 \AA$ MS, DCE. b) i. NBS, acetone, $\mathrm{H}_{2} \mathrm{O}$; ii. $\mathrm{HX}$, EDCl, DMAP, $\mathrm{CH}_{2} \mathrm{Cl}_{2}$. c) 2i, $\mathrm{Ph}_{3} \mathrm{PAuNTf}_{2}$, DCE. d) i. NBS, acetone, $\mathrm{H}_{2} \mathrm{O}$; ii. $\mathrm{HX}, \mathrm{EDCl}, \mathrm{DMAP}, \mathrm{CH}_{2} \mathrm{Cl}_{2}$ e e) i. 3-azidopropanol, $\mathrm{Ph}_{3} \mathrm{PAuNTf}_{2}(10 \mathrm{~mol} \%)$; ii. $\mathrm{H}_{2}, \mathrm{Pd} / \mathrm{C}, \mathrm{HCOOH}, \mathrm{HCOONH}{ }_{4}, \mathrm{THF}, t-\mathrm{BuOH}$; iii. $\mathrm{NH}_{2} \mathrm{NH}_{2} \cdot \mathrm{H}_{2} \mathrm{O}, \mathrm{MeOH}$

\section{Conclusion}

In conclusion, we have developed a highly efficient and stereoselective approach to the synthesis of GPSs by employing gold(I)-catalyzed glycosylation of phosphoric acid acceptors. The efficiency of this protocol was demonstrated by its universal application in preparing more than 45 complex GPSs, one-pot synthesis of linker-tethered GPS from Leishmania donovani, and an effective preparation of trisaccharide diphosphate from Hansenula capsulate via iterative elongation. Because of its exceptionally broad substrate scope, high $\alpha$-selectivity and inertness of phosphotriester toward chemical manipulations in comparison to phosphodiester, this strategy will offer new opportunities to create complex polyphosphosaccharides and incorporate diverse phosphosaccharides into bioactive molecules. 
Keywords: phosphosaccharide $\cdot$ glycosyl phosphate $\bullet$ stereoselectivity $\bullet$ glycosylation $\bullet$ gold(I) catalysis

\section{References}

1. Oka, N., Sato, K. \& Wada, T. Recent Progress in the Synthesis of Glycosyl Phosphate Derivatives. Trends Glycosci. Glyc. 24, 152-168, (2012).

2. Nikolaev, A. V., Botvinko, I. V. \& Ross, A. J. Natural Phosphoglycans Containing Glycosyl Phosphate Units: Structural Diversity and Chemical Synthesis. Carbohydr. Res. 342, 297-344, (2007).

3. Simpson, B. W. \& Trent, M. S. Pushing the Envelope: LPS Modifications and Their Consequences. Nat. Rev. Microbiol. 17, 403-416, (2019).

4. Ostash, B. \& Walker, S. Moenomycin Family Antibiotics: Chemical Synthesis, Biosynthesis, and Biological Activity. Nat. Prod. Rep. 27, 1594-1617, (2010).

5. Jennings, J. H., Rosell, K. G. \& Carlo, D. J. Structual Determination of the Capsular Polysaccharide of Streptococcus pneumoniae Type 19 (19F). Can. J. Chem. 58, 1069-1074 (1980).

6. Thibodeaux, C. J., Melançon III, C. E. \& Liu, H.-w. Natural-Product Sugar Biosynthesis and Enzymatic Glycodiversification. Angew. Chem. Int. Ed. 47, 9814-9859, (2008).

7. Plante, O. J., Palmacci, E. R., Andrade, R. B. \& Seeberger, P. H. Oligosaccharide Synthesis with Glycosyl Phosphate and Dithiophosphate Triesters as Glycosylating Agents. J. Am. Chem. Soc. 123, 9545-9554, (2001).

8. Levi, S. M., Li, Q., Rötheli, A. R. \& Jacobsen, E. N. Catalytic Activation of Glycosyl Phosphates for Stereoselective Coupling Reactions. Proc. Natl. Acad. Sci. USA 116, 35-39, (2019).

9. Lu, S.-R., Lai, Y.-H., Chen, J.-H., Liu, C.-Y. \& Mong, K.-K. T. Dimethylformamide: An Unusual Glycosylation Modulator. Angew. Chem. Int. Ed. 50, 7315-7320, (2011).

10. Fang, T., Mo, K.-F. \& Boons, G.-J. Stereoselective Assembly of Complex Oligosaccharides Using Anomeric Sulfonium Ions as Glycosyl Donors. J. Am. Chem. Soc. 134, 7545-7552, (2012).

11. Wang, L., Overkleeft, H. S., van der Marel, G. A. \& Codée, J. D. C. Reagent Controlled Stereoselective Synthesis of $\alpha$ Glucans. J. Am. Chem. Soc. 140, 4632-4638, (2018).

12. Yasomanee, J. P. \& Demchenko, A. V. Effect of Remote Picolinyl and Picoloyl Substituents on the Stereoselectivity of Chemical Glycosylation. J. Am. Chem. Soc. 134, 20097-20102, (2012).

13. Le Mai Hoang, K. \& Liu, X.-W. The Intriguing Dual-Directing Effect of 2-Cyanobenzyl Ether for a Highly Stereospecific Glycosylation Reaction. Nat. Commun. 5, 5051, (2014).

14. Benakli, K., Zha, C. \& Kerns, R. J. Oxazolidinone Protected 2-Amino-2-deoxy-d-glucose Derivatives as Versatile Intermediates in Stereoselective Oligosaccharide Synthesis and the Formation of $\alpha$-Linked Glycosides. J. Am. Chem. Soc. 123, 9461-9462, (2001).

15. Mensah, E. A. \& Nguyen, H. M. Nickel-Catalyzed Stereoselective Formation of $\alpha$-2-Deoxy-2-Amino Glycosides. $J$. Am. Chem. Soc. 131, 8778-8780, (2009).

16. Zulueta, M. M. et al. $\alpha$-Glycosylation by D-Glucosamine-Derived Donors: Synthesis of Heparosan And Heparin Analogues that Interact with Mycobacterial Heparin-Binding Hemagglutinin. J. Am. Chem. Soc. 134, 8988-8995, (2012).

17. Park, J., Kawatkar, S., Kim, J.-H. \& Boons, G.-J. Stereoselective Glycosylations of 2-Azido-2-deoxy-glucosides Using Intermediate Sulfonium Ions. Org. Lett. 9, 1959-1962, (2007). 
18. Garegg, P. J., Regberg, T., Stawinski, J. \& Strömberg, R. Nucleoside Hydrogenphophonates in Oligonucleotide Synthesis. Chem. Scr. 25, 59-62 (1986).

19. Westerduin, P., Veeneman, G. H., van der Marel, G. A. \& van Boom, J. H. Synthesis of the Fragment GlcNAc$\alpha(1 \rightarrow p \rightarrow 6)-G l c N A c$ of the Cell Wall Polymer of Staphylococcus Lactis Having Repeating N-acetyl-D-Glucosamine Phosphate Units. Tetrahedron Lett. 27, 6271-6274, (1986).

20. Ohira, S., Yamaguchi, Y., Takahashi, T. \& Tanaka, H. The Chemoselective O-Glycosylation of Alcohols in the Presence of a Phosphate Diester and Its Application to the Synthesis of Oligomannosylated Phosphatidyl Inositols. Tetrahedron 71, 6602-6611, (2015).

21. Sim, M. M., Kondo, H. \& Wong, C. H. Synthesis of Dibenzyl Glycosyl Phosphites Using Dibenzyl N,NDiethylphosphoramidite as Phosphitylating Reagent: an Effective Route to Glycosyl Phosphates, Nucleotides, And Glycosides. J. Am. Chem. Soc. 115, 2260-2267, (1993).

22. Fujita, S., Oka, N., Matsumura, F. \& Wada, T. Synthesis of Oligo( $\alpha$-D-Glycosyl Phosphate) Derivatives by a Phosphoramidite Method via Boranophosphate Intermediates. J. Org. Chem. 76, 2648-2659, (2011).

23. Westerduin, P., Veeneman, G. H., Marugg, J. E., van der Marel, G. A. \& van Boom, J. H. An Approach to the Synthesis of $\alpha$-L-Fucopyranosyl Phosphoric Mono- and Diesters via Phosphite Intermediates. Tetrahedron Lett. 27, 1211-1214, (1986).

24. Schmidt, R. R., Stumpp, M. \& Michel, J. $\alpha$ - and $\beta$-D-Glucopyranosyl Phosphates From $\alpha$-D-Glucoypyranosyl Trichloroacetimidates. Tetrahedron Lett. 23, 405-408, (1982).

25. Crich, D. \& Picard, S. Highly Stereoselective Synthesis of $\alpha$-D-Mannopyranosyl Phosphosugars. J. Org. Chem. 74, 9576-9579, (2009).

26. Hanessian, S., Lu, P.-P. \& Ishida, H. One-Step, Stereocontrolled Synthesis of Glycosyl 1-Phosphates, Uridine-5'diphosphogalactose, and Uridine-5'-diphosphoglucose from Unprotected Glycosyl Donors. J. Am. Chem. Soc. 120, 13296-13300, (1998).

27. Pale, P. \& Whitesides, G. M. Synthesis of Glycosyl Phosphates Using the Fraser-Reid Activation. J. Org. Chem. 56, 4547-4549, (1991).

28. Garcia, B. A. \& Gin, D. Y. Synthesis of Glycosyl-1-phosphates via Dehydrative Glycosylation. Org. Lett. 2, 2135-2138, (2000).

29. Edgar, L. J. G., Dasgupta, S. \& Nitz, M. Protecting-Group-Free Synthesis of Glycosyl 1-Phosphates. Org. Lett. 14, 4226-4229, (2012).

30. Plante, O. J., Andrade, R. B. \& Seeberger, P. H. Synthesis and Use of Glycosyl Phosphates as Glycosyl Donors. Org. Lett. 1, 211-214, (1999).

31. Ravidà, A., Liu, X., Kovacs, L. \& Seeberger, P. H. Synthesis of Glycosyl Phosphates from 1,2-Orthoesters and Application to in Situ Glycosylation Reactions. Org. Lett. 8, 1815-1818, (2006).

32. Nielsen, M. M. \& Pedersen, C. M. Catalytic Glycosylations in Oligosaccharide Synthesis. Chem. Rev. 118, 8285-8358, (2018).

33. Li, W. \& Yu, B. Gold-Catalyzed Glycosylation in the Synthesis of Complex Carbohydrate-Containing Natural Products. Chem. Soc. Rev. 47, 7954-7984, (2018).

34. Dorel, R. \& Echavarren, A. M. Gold(I)-Catalyzed Activation of Alkynes for the Construction of Molecular Complexity. Chem. Rev. 115, 9028-9072, (2015). 
35. Fürstner, A. \& Davies, P. W. Catalytic Carbophilic Activation: Catalysis by Platinum and Gold $\pi$ Acids. Angew. Chem. Int. Ed. 46, 3410-3449, (2007).

36. Li, Y., Yang, Y. \& Yu, B. An Efficient Glycosylation Protocol with Glycosyl ortho-Alkynylbenzoates As Donors Under the Catalysis of $\mathrm{Ph}_{3}$ PAuOTf. Tetrahedron Lett. 49, 3604-3608, (2008).

37. Zhu, Y. \& Yu, B. Highly Stereoselective $\beta$-Mannopyranosylation via the 1- $\alpha$-Glycosyloxy-isochromenylium-4-gold(I) Intermediates. Chem. Eur. J., (2015).

38. Tvaroŝka, I. \& Bleha, T. in Adv. Carbohydr. Chem. Biochem. Vol. 47 (eds R. Stuart Tipson \& Derek Horton) 45-123 (Academic Press, 1989).

39. Schumann, B. et al. Nucleophile-Directed Stereocontrol Over Glycosylations Using Geminal-Difluorinated Nucleophiles. Angew. Chem. Int. Ed. 55, 14431-14434, (2016).

40. Huang, X., Huang, L., Wang, H. \& Ye, X.-S. Iterative One-Pot Synthesis of Oligosaccharides. Angew. Chem. Int. Ed. 43, 5221-5224, (2004).

41. Slattegard, R. et al. Synthesis of Structures Corresponding to the Capsular Polysaccharide of Neisseria meningitidis group A. Org. Biomol. Chem. 3, 3782-3787, (2005).

42. Zhu, Y. \& Yu, B. Characterization of the Isochromen-4-yl-gold(I) Intermediate in the Gold(I)-Catalyzed Glycosidation of Glycosyl ortho-Alkynylbenzoates and Enhancement of the Catalytic Efficiency Thereof. Angew. Chem. Int. Ed. 50, 8329-8332, (2011).

43. Matthijs, G. et al. Mutations in PMM2, a Phosphomannomutase Gene on Chromosome 16p13 in CarbohydrateDeficient Glycoprotein Type I Syndrome (Jaeken syndrome). Nat. Genet. 16, 88-92, (1997).

44. Hollaus, R. et al. Chemical synthesis of Burkholderia Lipid A modified with Glycosyl Phosphodiester-Linked 4-amino4-deoxy-beta-L-Arabinose And Its Immunomodulatory Potential. Chem. Eur. J. 21, 4102-4114, (2015).

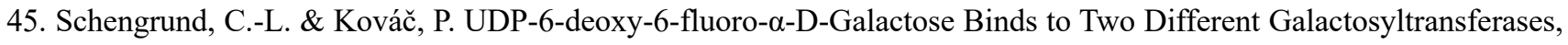
but Neither can Effectively Catalyze Transfer of the Modified Galactose to the Appropriate Acceptor. Carbohydr. Res. 319, 24-28, (1999).

46. Jambal, I., Kefurt, K., Hlaváčková, M. \& Moravcová, J. Synthesis of 2-fluoro and 4-fluoro Galactopyranosyl Phosphonate Analogues of UDP-Gal. Carbohydr. Res. 360, 31-39, (2012).

47. Bucher, C. \& Gilmour, R. Fluorine-Directed Glycosylation. Angew. Chem. Int. Ed. 49, 8724-8728, (2010).

48. Majumdar, D., Elsayed, G. A., Buskas, T. \& Boons, G.-J. Synthesis of Proteophosphoglycans of Leishmania major and Leishmania mexicana. J. Org. Chem. 70, 1691-1697, (2005).

49. Zhang, Z. et al. Programmable One-Pot Oligosaccharide Synthesis. J. Am. Chem. Soc. 121, 734-753, (1999).

50. Wu, Y., Xiong, D.-C., Chen, S.-C., Wang, Y.-S. \& Ye, X.-S. Total Synthesis of Mycobacterial Arabinogalactan Containing 92 Monosaccharide Units. Nat. Commun. 8, 14851, (2017).

51. Zhang, Y. et al. Modular Synthesis of Nona-Decasaccharide Motif from Psidium guajava Polysaccharides: Orthogonal One-Pot Glycosylation Strategy. Angew. Chem. Int. Ed. 59, 7576-7584, (2020).

52. Nikolaev, A. V., Ivanova, I. A. \& Shibaev, V. N. The Stepwise Synthesis of Oligo(glycosyl phosphates) via Glycosyl Hydrogenphosphonates. The Chemical Synthesis of Oligomeric Fragments From Hansenula capsulata Y-1842 Exophosphomannan And from Escherichia coli K51 Capsular Antigen. Carbohydr. Res. 242, 91-107, (1993).

53. Crich, D. \& Smith, M. 1-Benzenesulfinyl Piperidine/Trifluoromethanesulfonic Anhydride: A Potent Combination of Shelf-Stable Reagents for the Low-Temperature Conversion of Thioglycosides to Glycosyl Triflates and for the Formation of Diverse Glycosidic Linkages. J. Am. Chem. Soc. 123, 9015-9020, (2001). 


\section{Supplementary Files}

This is a list of supplementary files associated with this preprint. Click to download.

- SI1ProcedureandCharacterization.pdf

- SI2NMRSpectra.pdf 